\title{
@prenda: Jogo Educativo
}

\author{
Walkiria Cordenonzi ${ }^{1}$, Vanessa M. Cardoso ${ }^{1}$, Silvio Normey Gomez ${ }^{1}$, Gill Velleda \\ Gonzales $^{1}$, Francielli Vasconcellos ${ }^{1}$ \\ ${ }^{1}$ IFSUL - Câmpus Santana do Livramento AV. Paul Harris 410 - S. Livramento - RS - \\ Brazil \\ \{walkiriacordenonzi, vanessacardoso, silviogomez,gillgonzales\}@ifsul.edu.br
}

Resumo. Este artigo apresenta o objeto de aprendizagem (OA) @aprenda, que foi desenvolvido, na forma de um jogo de perguntas e respostas, e vem sendo adaptado para atender as demandas do curso técnico subsequente em Informática para Internet do IFSul, Câmpus Santana do Livramento, como tentativa de reduzir os indices de reprovação e evasão, proporcionando ao estudante a oportunidade não só de testar seus conhecimentos mas de esclarecer dúvidas (através de dicas) e até mesmo se compreender conteúdos. Além disso, pensando no perfil alunos dos cursos noturnos, ele foi projetado para ser utilizado em dispositivos móveis, possibilitando o acesso de diferentes lugares.

Abstract. The present paper describes the Learning Object (LO), @aprenda, developed in the form of game of questions and answers. The LO has been adapted to support the demands of the Web Programming Technical course of the Federal Institute of Science and Technology ministered in the Santana do Livramento campus. @ aprenda aims to decrease the percentage of disapproval and course evasion as well as providing the students with the opportunity to test the knowledge, fill gaps and achieve a better understanding of the different subjects. Moreover, looking for broad usage and considering the night time students, the application can be accessed from mobile devices due to its responsive design.

\section{Cenário de uso}

O Instituto Federal Sul-Rio-Grandense, Câmpus Santana do Livramento, está localizado na fronteira com o Uruguai (Livramento/Rivera) e oferta vários cursos técnicos, com a peculiaridade de ser Binacional. Estes cursos ditos binacionais se formam a partir da disponibilização de $50 \%$ das vagas para brasileiros e os $50 \%$, restantes, para uruguaios. Capitaneado pela Secretaria de Educação Profissional e Tecnológica (Setec) do Ministério da Educação, em parceria com o Instituto Federal Sul-rio-grandense e o Consejo de Educación Tecnico Profesional da Universidad del Trabajo Del Uruguay (CETP-UTU) (Mec, 2011). O ineditismo deste curso se dá no que se refere a revalida dos diplomas, ou seja, são automaticamente reconhecidos nos dois países. Os alunos desses cursos têm a total liberdade de se comunicar e escrever no seu idioma materno (língua portuguesa ou língua espanhola) no ambiente educativo.

Entre os cursos oferecidos, pelo campus, está o curso Técnico em Informática para Internet, na modalidade subsequente, que tem suas atividades no período noturno. É sabido que os índices tanto de evasão quanto de reprovação são muito elevados em cursos noturnos, pois para grande parte dos alunos o estudo ocupa um "segundo plano", uma vez que tem responsabilidades financeiras e familiares, e ao se depararem com grandes dificuldades acabam abandonando os cursos. Tendo em vista este fato e a complexidade que um curso de informática representa para a maioria dos nossos estudantes, que chegam muitas vezes desconhecendo a estrutura do curso, e como tentativa de dar suporte e motivação a esses alunos é que iniciou-se este projeto com o grupo de alunos que caracterizam futuras evasões, ou seja, que demonstraram precisar de um auxílio extra. 
VI Congresso Brasileiro de Informática na Educação (CBIE 2017)

Anais dos Workshops do VI Congresso Brasileiro de Informática na Educação (WCBIE 2017)

Percebeu-se, durante três semestres, que os alunos do primeiro, em sua maioria, reprovaram nas disciplinas de Lógica e Algoritmos e FMC (Fundamentos Matemáticos para Computação) e acabavam evadindo, depois do primeiro ou segundo insucesso.

É neste contexto que o@prenda foi projetado.

\section{Desenvolvimento}

O projeto do@prenda está sendo desenvolvido desde 2014 com alunos do curso técnico em Informática para Internet, modalidade Subsequente e possui três módulos: Administrador (MA), Professor (MP) e Jogo (MJ).

Os dois primeiros módulos (MA e MP) foram projetados e desenvolvidos utilizando o ciclo de vida Incremental e Iterativo. Estes módulos são de pouca complexidade e interação com usuário.

Já o MJ é bastante complexo, dado sua interação com o usuário. No desenvolvimento deste módulo, iniciado em 2015, alguns métodos foram utilizados porque variou a quantidade de programadores envolvidos (nesse desenvolvimento, o número de alunos bolsistas foi de 10 e voluntários simultaneamente). Em determinados períodos a programação extrema (XP -eXtreme Programming) - junta dois programadores foi a decisão mais adequada. Aconteceram também, na maioria do tempo, a abordagem em Espiral.

Quanto ao XP pode-se verificar que o tempo de desenvolvimento foi reduzido os defeitos de software, e aumentou a satisfação dos desenvolvedores.

Durante o desenvolvimento, a equipe sempre teve presente requisitos como, escalabilidade, manutenibilidade, entre outros.

Tecnologicamente optou-se por utilizar um SGBDOR (Sistema de Gerenciamento de Banco de Dados Objeto Relacional) PostgreSql, baseado no POSTGRES, versão 4.2. PHP 5.6.8 e Netbeans IDE foram utilizados.

Para o desenvolvimento do MA e MP foi estabelecido utilizar a linguagem de programação Server-Side PHP 5.6.8 juntamente com o Web Server Apache 2.0 Handler, ambos sendo uma boa solução para o sistema web, e para melhor apresentação de algumas funcionalidades do software, foi utilizado JavaScript.

Este aplicativo foi submetido a vários testes de usabilidade e testes de aceitação.

Estes últimos (aceitação) foram:

Grupo de alunos matriculados na disciplina de PSDB I ( Projeto de Sistemas de Banco de Dados), na subárea de SQL, no idioma Português.

Grupo de alunos matriculados nas disciplinas de Lógica e Algoritmos e de Fundamentos Matemáticos para computação. A característica desse grupo é que todos os alunos estão cursando pela segunda vez ambas disciplinas. A área de Lógica\&Matemática, subárea Programa\&Funções, com questões em Português.

Ao propor um jogo para o aluno, sabe-se que este produz um encantamento entre os jogadores, pois estes almejam a vitória, tentando compreender como o jogo funciona e quais são as respostas corretas. Com isso tem-se um jogador motivado e consequentemente um aluno aprendendo/brincando. Segundo (Fialho, 2007), "A exploração do aspecto lúdico, pode se tornar uma técnica facilitadora na elaboração de conceitos, no reforço de conteúdos, na sociabilidade entre os alunos, na criatividade e no espírito de competição e cooperação, tornando esse processo transparente, ao ponto que 
o domínio sobre os objetivos propostos na obra seja assegurado". Complementando, os jogos propiciam também "o desenvolvimento do raciocínio lógico", segundo Borin (2004).

Dentre algumas vantagens com relação aos jogos educativos (e que se encontram implementadas no@prenda) pode-se citar (Grando, 2011):

fixação de conceitos já aprendidos de uma forma motivadora para o aluno; introdução e desenvolvimento de conceitos de difícil compreensão;

aprender a tomar decisões e saber avaliá-las;

significação para conceitos aparentemente incompreensíveis; propicia o relacionamento das diferentes disciplinas (interdisciplinaridade);

o jogo requer participação ativa do aluno na construção do seu próprio conhecimento;

a utilização dos jogos é um fator de motivação para os alunos, os jogos favorecem a competição "sadia" e o resgate do prazer em aprender.

O objetivo foi desenvolver o jogo@prenda, que reúne os conceitos supra citados: é um objeto de aprendizagem, projetado para ser utilizado em dispositivos móveis, proporcionando o desenvolvimento de diversos conteúdos (qualquer assunto pode ser inserida questões), sendo assim interdisciplinar, de forma lúdica através de um jogo educativo. Sendo assim, O @prenda pode ser utilizado em qualquer nível de ensino, de forma interdisciplinar e multi-idioma (dado o contex to no qual está inserido).

Cabe salientar que os primeiros testes de aceitação foram realizados em sala de aula, acompanhados dos professores e alunos que desenvolveram e logo após, foi aplicado um questionário junto aos jogadores com o intuito de registrar os erros encontrados, a usabilidade do jogo e as sugestões.

\section{Apresentação do Software}

O@prenda consiste em um jogo (pode ser acessado por dispositivos móveis) que desafia o aluno em um conjunto de perguntas e respostas (quiz) de múltipla escolha revisando os conteúdos já vistos pelo aluno, anteriormente em aula. A fim de compreender o nível de aprendizagem do aluno, as respostas são armazenadas pelo sistema para acompanhamento do professor e análise dos resultados contidos no@prenda. Conforme já comentado o@prenda possui três módulos: Administrador (MA), Professor (MP) e Jogo (MJ).

\section{1 . Módulo do Administrador -MA}

É neste módulo que os parâmetros do jogo são definidos conforme pode ser: áreas, subáreas, idiomas, autorizações dos usuários (administrador, professor ou jogador), entre outros, que podem ser visualizados na Figura 01.

Tem-se três níveis de usuário: (1) administrador; (2) professor e (3) aluno. O administrador, conforme o nome já indica tem acesso total ao sistema. Este módulo pode ser acessado em http://projetos.santana.ifsul.edu.br/aprenda/site/. O login para usuário administrador é: app e a senha: app.

Olá: wal Nivel: ADM Principal Usuários Instituições Idiomas Países Nivel Área Sub-Área Socioeconômico- Mineração- Sair

Figura 01-Interface do Administrador

\section{2 . Módulo do Professor -MP}


VI Congresso Brasileiro de Informática na Educação (CBIE 2017)

Anais dos Workshops do VI Congresso Brasileiro de Informática na Educação (WCBIE 2017)

O papel no professor no jogo é inicialmente cadastrar as perguntas. Para cada pergunta inserida no jogo, o professor deverá selecionar o idioma da questão, a área e subárea do conhecimento ao qual pertence, conforme pode ser visualizado na Figura 02.

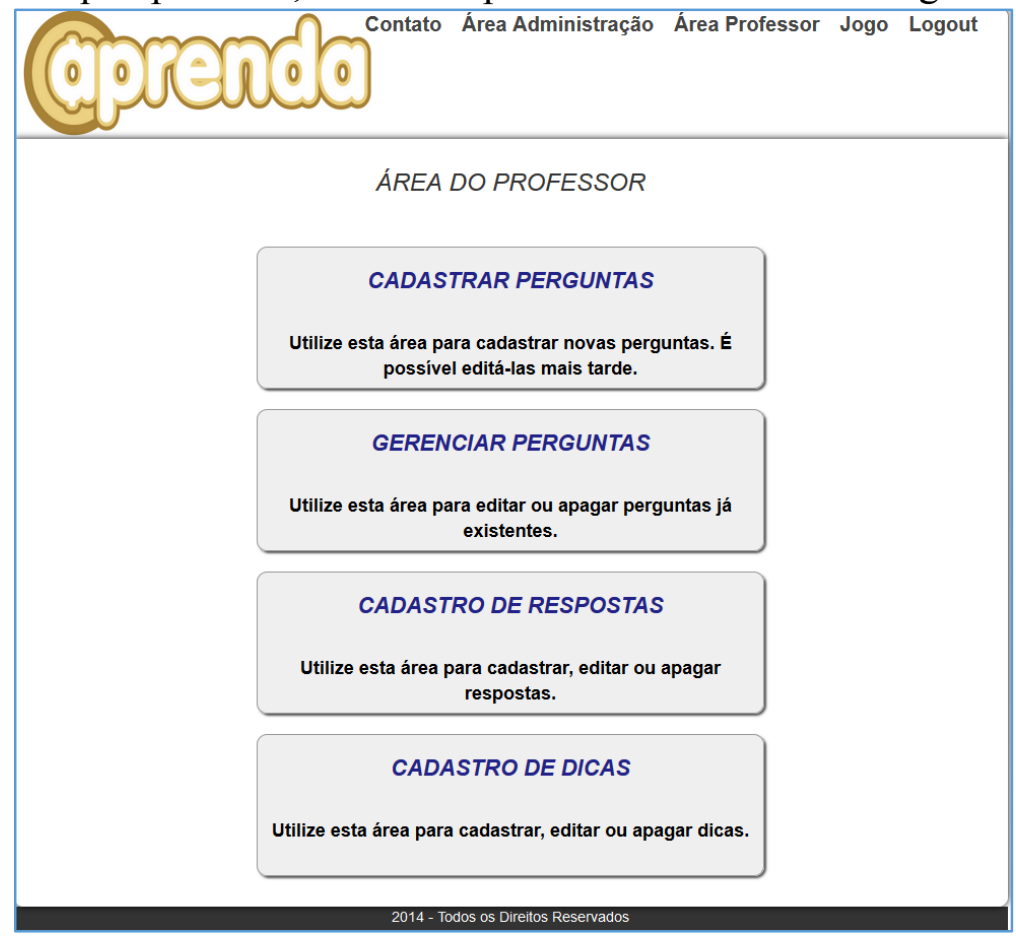

Figura 02 -Interface do professor

Ao escolher cadastrar perguntas o professor deve preencher os dados em quatro passos. No Passo 1 - deve-se preencher os dados como área, subárea, país, idioma, etc.

Todas as questões possuem um grau de dificuldade (fácil, médio, difícil) e podem estar associadas a dicas, desde que previamente cadastradas, e também estas estão relacionadas a um idioma (Figura 03). Para cada questão cadastrada deve-se relacionar cinco respostas e determinar qual é a correta. No passo 2 -digita-se a pergunta, conforme Figura 04.

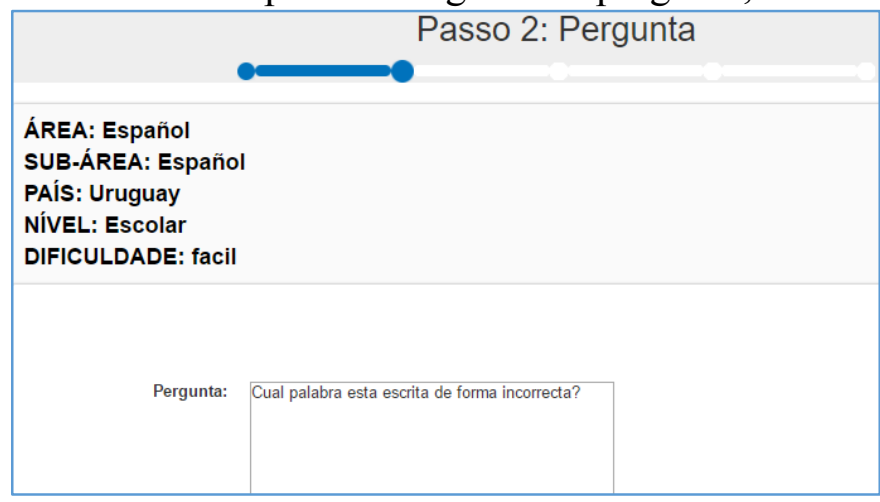

Figura 03-Cadastro de Perguntas -Passo 02 
VI Congresso Brasileiro de Informática na Educação (CBIE 2017)

Anais dos Workshops do VI Congresso Brasileiro de Informática na Educação (WCBIE 2017)

No Passo 3, deve-se cadastrar 5 respostas e determinar qual delas é a correta. Este processo pode ser visualizado na Figura 04.

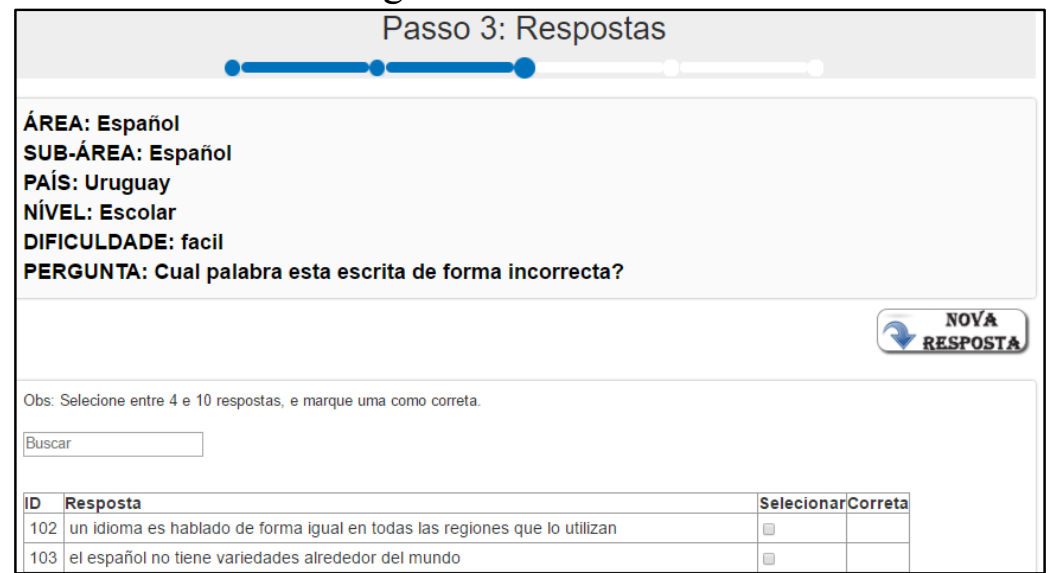

Figura 04-Cadastro de Perguntas -Passo 03

No último passo (4) relacionar ou inserir Dicas a esta questão (Figura 05). O professor poderá alterar ou apagar as questões, as respostas ou as dicas na mesma interface.

O usuário cuja permissão é de professor, acessa o seguinte link: http://projetos.santana.ifsul.edu.br/aprenda/site/areaprofessor.php

O login para usuário professor é: app e a senha: app.

\subsection{Módulo do Jogo}

Os demais usuários - que são os jogadores - deverão fazer seu cadastro e jogar através do seguinte link:http://projetos.santana.ifsul.edu.br/aprenda/site/login_usuario.php.

Recomenda-se que iniciar o jogo o usuário/jogador siga as instruções que se encontram no tutorial, disponível no seguinte endereço: http://ecompartindo.santana.ifsul.edu.br/

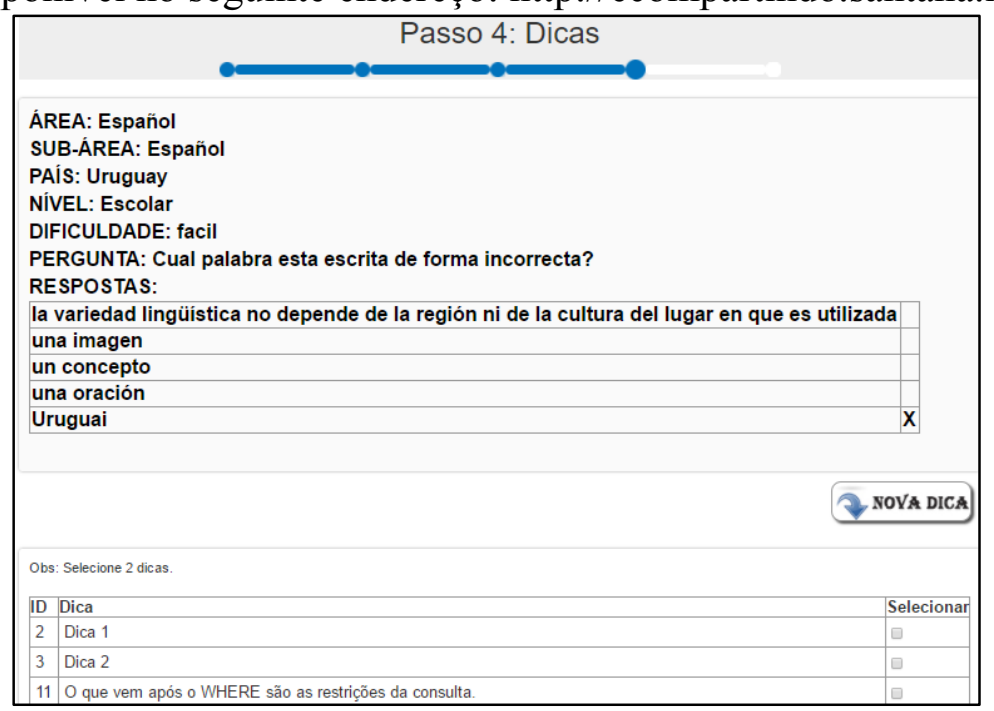

Figura 05-Cadastro de Perguntas -Passo 04

Observando a Figura 06, o jogador após fazer suas escolhas com relação a área, subárea e idioma que irá jogar, passa então ao jogo. Nesta etapa as questões cadastradas previamente pelo professor são sorteadas para sua apresentação. Cada questão possui um conjunto de 5 respostas, sendo somente uma a correta. Novamente o sistema sorteia a ordem das respostas. 
VI Congresso Brasileiro de Informática na Educação (CBIE 2017)

Anais dos Workshops do VI Congresso Brasileiro de Informática na Educação (WCBIE 2017)

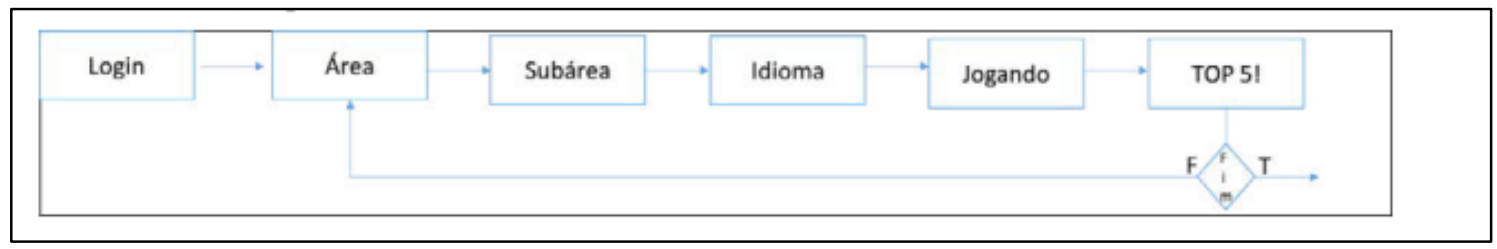

Figura 06 - Funcionamento do Jogo

O reconhecimento e gratificação dos alunos mediante o jogo se dá por meio de moedas virtuais chamada IFCOINS (IFSUL + COINS). Cada questão inicia com 100 IFCOINS (moeda virtual do jogo) e o jogador acumula suas moedas. Cada tentativa errada ou uso de Dica o jogador perde 20 IFCOINS. No final do jogo é apresentada uma lista denominada TOP 5! (lista com os cinco jogadores que mais acumularam pontos). Dessa forma o aluno poderá elevar sua pontuação geral no ranking destacando as melhores posições dos jogadores. A partir desta funcionalidade, sob o ponto de vista pedagógico, pretende-se estimular o uso do jogo e assim a popularidade dos melhores jogadores. Caso o jogador não figure nesta lista, sua pontuação é mostrada na tela, conforme pode ser vista na Figura 07.

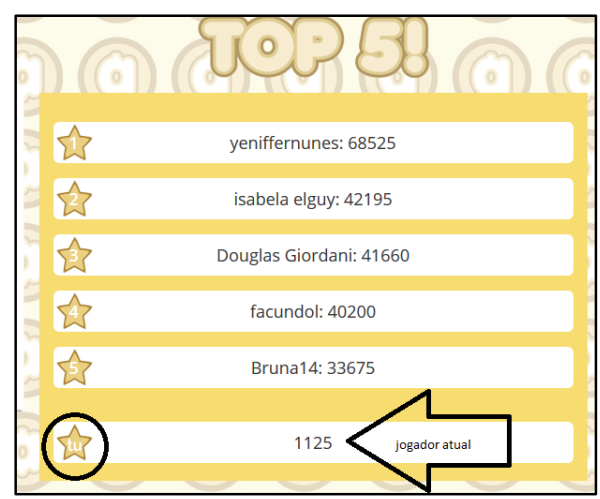

Figura 07 - Lista de TOP 5!

A opção de PULAR permite ao jogador não responder a questão mostrada e portanto não perde suas moedas. $\mathrm{O}$ vídeo do @prenda está disponível em: $<<$ https://youtu.be/pzp_Xg_1Z_w >>

\section{Considerações finais}

O@prenda começou a ser desenvolvido em 2014 e vem sendo alterado e ajustado para melhorar o processo de aprendizagem.

Durante os dois anos de construção, muitos foram os testes de aceitação deste produto. Percebeu-se, nas primeiras interações, que os jogadores estavam memorizando a resposta das questões. Isso ocorreu, pois, o banco de questões da área e subárea escolhida era composto por apenas 20 questões. Mudanças foram implementadas e implementou-se a randomização das perguntas e da ordem de aparecimento das respostas.

Para um dos casos de test para validação do projeto (em Cordenonzi, 2016) foi escolhido um grupo de 14 alunos, que estavam repetindo as disciplinas de Fundamentos Matemáticos e Lógica e Algoritmos do curso de Informática para Internet, que caracterizam as possíveis evasões. No curso, as duas disciplinas foram pensadas e planejadas para abordarem os mesmos conteúdos concomitantemente, possibilitando um trabalho interdisciplinar e complementar, sendo assim, a maioria dos estudantes que não obtiveram sucesso em uma, tampouco conseguiram desempenho satisfatório na outra, ou seja, para avaliação do impacto do jogo, foi utilizado, também, um instrumento de 
avaliação escrita aplicado na disciplina de Lógica, medindo os conhecimentos adquiridos nas duas áreas.

Neste semestre foi proposto aos alunos que fizessem uso do@prenda, pelo menos uma hora por semana, nas subáreas correspondentes às disciplinas (Fundamentos Matemáticos - Funções e Lógica e Algoritmos - Programação e Funções). Esta interação foi monitorada durante três semanas. As questões do jogo foram criteriosamente selecionadas para perfazerem todo o conteúdo. Após esse período, um teste foi elaborado sobre os conceitos abordados pelo jogo. Ao final do período proposto, constatou-se que a média de acessos, desse grupo ao jogo foi de 4,85 por aluno, ou seja, quase 5 vezes maior quando comparada ao número de vezes com que realizam atividades em uma lista de exercícios. O número de perguntas acessadas e respondidas, pelos jogadores, foi de 1366.

Foi realizada uma atividade teórica após a utilização do OA da qual 10, dos 14, estudantes participaram e os resultados foram que dois alunos não responderam; dos 8 alunos que responderam, $60 \%$ acertaram as habilidades trabalhadas no jogo;e a maioria dos jogadores com maior pontuação, corresponde a aqueles que mais fizeram tentativas (mesmo com a penalidade dos pontos), ou seja, realmente o OA auxiliou na revisão dos conteúdos. O resultado está publicado em Cardoso e Cordenonzi (2017).

A partir dos resultados obtidos neste estudo, pode-se destacar a aceitação e disponibilidade dos estudantes, deste grupo selecionado, quanto à utilização do @prenda, uma vez que, na visão deles, apresenta-se de forma mais "amigável" e "convidativa" que as usuais listas de exercícios. Acredita-se que o professor, ao conhecer o jogador/aluno e suas dificuldades, e até mesmo características pessoais (percebidas através dos hábitos: Tentativas, tempo de jogo e horários de acesso) possa ser proativo em suas ações de ensino, possibilitando assim uma aprendizagem mais individualizada. E por mostrar-se atraente, e de fácil utilização espera-se que o @prenda ganhe espaço, cada vez maior, no cotidiano do estudante, como forma de estudo e revisão de conteúdos e conceitos. Temse a pretensão de desvincular o processo de aprendizagem a um lugar, isto é, permitir a mobilidade do jogador, independente de tempo e espaço. Sendo o @prenda um REA, pode-se promover a inovação pedagógica e relevância, evitando o ensino voltado para um formato manual.

Atualmente o OA conta com três disciplinas: Lógica e Algoritmos, Banco de dados e Fundamentos Matemáticos, disciplinas vistas como mais "difíceis" no início do curso. Como trabalhos futuros pretende-se expandir para as demais disciplinas do curso e aumentar a quantidade de questões e posteriormente ofertá-lo para os demais professores de outros cursos e modalidades de ensino.

\section{References}

Borin, Júlia. Jogos e resolução de problemas: uma estratégia para as aulas de matemática. $5^{\mathrm{a}}$. ed. São Paulo: CAEM / IME-USP, 2004, 100p.

Grando, R. C. O jogo na educação: aspectos didático-metodológicos do jogo na educação matemática. Unicamp, 2001.

Cordenonzi, W. et al. O Uso do @prenda como Recurso Educativo Digital. XXXVI Congresso da Sociedade Brasileira de Computação. Página 692-695. 2016.

Cardoso, V.M., Cordenonzi,W. "@PRENDA: Objeto de Aprendizagem aliado ao Ensino da Matemática". $7^{\circ}$ Congreso Uruguayo de Educación Matemática. 2017. Ferguson, R. The State Of Learning Analytics in 2012: A Review and Future 
VI Congresso Brasileiro de Informática na Educação (CBIE 2017)

Anais dos Workshops do VI Congresso Brasileiro de Informática na Educação (WCBIE 2017)

Challenges.Technical Report KMI-12-01, Knowledge Media Institute, The Open University, UK,2012. 